\title{
Analysis and Application of Compound Teaching Theory of Aerobics and Weightlifting Courses in the New Era
}

\author{
Gong Yan \\ Jiangxi Science and Technology Normal University, Nanchang, Jiangxi, 330003
}

Keywords: New Age, Weightlifting, Aerobics, Compound Teaching

\begin{abstract}
In the new era, the teaching content of aerobics and weightlifting has been reorganized and integrated. This paper analyzes the teaching content system of aerobics and weightlifting with the method of literature and comparative analysis. Based on the theory of physical education and education, a systematic comparative analysis is carried out, and the problems and the integration of aerobics and weightlifting courses are explored in depth. In the process of inquiry, we can see that the compound teaching mode can effectively improve the quality of teaching, optimize the teaching resources of aerobics, and also meet the purpose and needs of sports talents in the new era.
\end{abstract}

\section{Introduction}

In the new era of development, the school curriculum teaching system has entered the stage of the reform. The key problem to be considered is how to innovate the new school sports related curriculum and the effective and rational use of school sports resources. Compound teaching model proposed in this paper is to improve the teachers' quality of teaching and enhance the teaching effect and help students improve their physical quality, strengthen the weak links for physical basis, mainly by setting the content of Aerobics specialty development, talents cultivation and integration optimization teaching [1-2]. On the basis of social needs, the training method is formulated, and the complementarity of aerobics and weightlifting is highlighted to show the advanced nature of the complex course.

\section{The Meaning and Related Theory of Compound Teaching in the New Era}

\subsection{The meaning of Compound Teaching}

Composite teaching can be attributed to the category of education system, is a new teaching method of agility, can promote learners enthusiasm and improve the teaching efficiency, innovation is a kind of educational experience. The birth of the compound teaching has its realistic foundation, for example, in the new era, it is still limited by some mountainous rural schools which are distracted, distracted and inconvenient, which lead to the shortage of school teachers. Under difficult conditions, teachers can only use one classroom, and use different textbooks in the same class to teach students with different ages in a classroom [3]. Compound teaching is aimed at different teaching methods that are different in talent, grade, class and culture basis, which is a notable feature of compound teaching.

In today's sports teaching many ways, compound teaching has its outstanding effect. Based on the variety of sports, its training methods have differences and similarities. However, things are universally related, but they also play a role of mutual influence. They are related to each other in terms of strength, flexibility, speed, quality, endurance and flexibility. In this paper, a new era under the weight of aerobics and the characteristics of the experimental teaching scheme combined, the two curriculum organization teaching as teaching tasks, teaching objectives, teaching organization and teaching methods on the basis of this, between their content for the integrated nature of the fusion teaching system. The compound teaching is based on the actual situation of the students, and carries out the changing teaching guidance at the same time to assist the practice of the teaching [4]. It can quickly absorb the theory of motion correlation and apply it to practical training of sports 
skills. In order to achieve the goal of training effect, optimize the teaching effect.

\subsection{The related theory of Compound Teaching}

First of all, from the perspective of pedagogy, the compound teaching in the new era is not only a simple and superficial combination teaching course, but also an adaptation to the development of the times and the progress of society. Reference compound talents guiding ideology, talent demands and characteristics of the subject as catalyst, professional teaching method will want to roll the link, control and management of teaching content, teaching objectives, teaching methods, teaching evaluation and organization, the challenge of talent cultivation of innovative new generation theory and the reform practice teaching. Secondly, on the basis of the level of physical education, teaching, group compound teaching project teaching, the teaching goal is to determine the educated body basic quality, sports ability, basic understanding of basic level information, and then using the target management and standard evaluation system [5-6]. Compound teaching has its sensitive and free characteristics, which not only helps to train the students' independent spirit and innovative thinking, but also can fully display the teacher's leading role.

In the new era, students' self-learning level, thinking and self-criticism ability will be improved in the process of compound teaching experience. Students can gradually form good habits of attention concentration and focus on disturbance in teaching. To promote sports development and enhance students' physical quality is the core purpose of school physical education curriculum. Combined curriculum teaching can combine students' psychological state, physiological status, physical fitness and other characteristics, as well as understand the interest trend of various sports categories [7]. In the perspective of lifelong benefit training, the compound teaching theory has its positive guiding significance. In terms of sports awareness, habits and abilities of sports, this paper expounds the purpose of the inquiry and analysis of compound curriculum.

\section{An Analysis of the Compound Teaching Idea of Aerobics and Weightlifting in the New Era}

Sports and fitness is a popular direction in the new era, with the popularity of fitness and promote the sports concept in universities, colleges and universities aerobics course also pay close attention to the public under the like a raging fire started, in the emerging era of development has attracted more and more attention. As the characteristics of aerobics sports and weightlifting sports belong to the strength of the application, at the same time, in reality survey, aerobics courses and weightlifting courses have their fusion trend. Therefore, we analyze and discuss the teaching methods of aerobics and weightlifting, and point out the center of the two, improve teaching efficiency and ensure students' growth in all aspects [8].

\subsection{The convergence of strength}

The characteristics of weightlifting sports is to focus on the physical quality of the students and the students' power technology, a project using the specific method of weight lifting exercise. The characteristic of aerobics is to use special movements, techniques and methods, exercises and devices to shape and strengthen muscles, so as to achieve physical and mental fitness and physical fitness [9-10]. Thus, in the movement strength of Aerobics in common with weightlifting courses, so it is worthy of attention in the course of teaching is weightlifting is the extension of power, with greater weight lifting as the goal. The aerobics also need to control the power of practice, but the development power of relative, grasping, stretching should be appropriate, clean and jerk and skilled.

\subsection{The class teaching of the students' Aerobics Course}

The teaching of Aerobics emphasizes the rationality of the use of strength. The students of aerobics teaching are divided into three levels, primary, intermediate and advanced. The aerobics exercise of junior students should pay attention to the rational use of force, ensure the regular posture of body movement and avoid the harm to the body, focus on developing muscle tissue and showing the graceful shape of muscle. Therefore, we should introduce the right exercise methods in 
weightlifting. We should guide students to control their strength, correct posture and avoid bodily injury. In the aerobics teaching will also be some basic movements in weightlifting to be integrated, such as the clean and jerk action [11]. Clean and jerk action is the prerequisite of rational use of power, can effectively guide the students how to force, what time force, with much force and how efficient use of power. When exercising aerobics for students, we should use weightlifting's scientific training method, and properly control the link between labor and labor, so that we can enhance students' self-consciousness in Aerobics learning and highlight the superiority effect of exercise.

\subsection{Students' weight lifting theory of Aerobics classification}

In ordinary teaching, there is no effective grading measures between aerobics and weightlifting courses, so teachers usually do not divide the weight class into mixed teaching. Therefore, classification assessment in weight grading hope for schools to weight negative assessment, considering the students can grasp and jerk, and my weight is compared. Then, the aerobics students will be able to carry out muscle tone and power levels of aerobics exercise in accordance with the test mode of weightlifting classification, such as reference arm movement weight lifting, lifting dumbbells, sit ups, chest training and other auxiliary actions to the aerobics of the pectoralis major muscle, two head, Philip ABS were deltoid, testing requirements, and weight, can also be compared to other areas, such as weight, weight and weight ratio and power ratio for classification. The classification of middle and senior athletes in weightlifting programs can be applied to aerobics exercise and display.

\section{Conclusion}

By expounding the teaching meaning of compound teaching and the origin of its theoretical basis, combining with analyzing the practical application of compound teaching in the new era, this paper expands the professional teaching way. For example, the aerobics course and weightlifting course combined type teaching system construction, education, sports and other disciplines as philosophy foundation. Find the co integration between the two, in order to help students overcome due to the professional division of project meticulous knowledge shortcomings, the professional teaching content curriculum has been optimized and integrated, so as to realize students' innovative practical ability, provide a "composite" professional talents for the new era of development.

\section{References}

[1] Haro F B, Orozco P S P, Méndez J A J, et al. Application of a geometric and mathematical model to the biomechanics of the lumbar region in weightlifting athletes. [J]. Journal of Negative and, 2016, 1: págs. 201-209.

[2] Suchomel T J, Comfort P, Stone M H. Weightlifting Pulling Derivatives: Rationale for Implementation and Application. [J]. Sports Medicine, 2015, 45(6):823.

[3] Xu Y. The Analysis of Pre-Competition Mental State of Women's Weightlifting Athletes in Anhui Province[J]. Journal of Anhui Sports Science, 2016.

[4] Zamora D, Rodas P, Pauzhi W, et al. Analysis of the optimal trajectory in weightlifting in style "snatch"[C]// Electrical, Electronics Engineering, Information and Communication Technologies. IEEE, 2016:219-224.

[5] Brown J C, Schmitz K H. Weight Lifting and Physical Function among Breast Cancer Survivors: A Post Hoc Analysis of a Randomized Controlled Trial. [J]. Journal of Clinical Oncology Official Journal of the American Society of Clinical Oncology, 2015, 33(19):2184.

[6] Hackett D, Davies T, Soomro N, et al. Olympic weightlifting training improves vertical jump height in sportspeople: a systematic review with meta-analysis. [J]. British Journal of Sports Medicine, 2015, 50(14): bjsports-2015-094951. 
[7] Sosnilo V. Weight structures in localizations (revisited) and the weight lifting property[J]. Mathematics, 2015.

[8] Kiyici F. Metabolic and Lipid Profile of Middle-aged Sedentary Women doing Aerobic Exercise Plus Weightlifting. [J]. Procedia - Social and Behavioral Sciences, 2014, 116:3935-3939.

[9] Saroglakis G, Kritikos A, Arzoglou P, et al. The effect of aerobic and weight lifting exercise on blood clotting[J]. Journal of Physical Education \& Sport, 2014, 14.

[10] Gerber M, Brand S, Elliot C, et al. Aerobic exercise, ball sports, dancing, and weight lifting as moderators of the relationship between stress and depressive symptoms: an exploratory cross-sectional study with swiss university students[J]. Perceptual \& Motor Skills, 2014, 119(3):679.

[11] Scott C B. The effect of time-under-tension and weight lifting cadence on aerobic, anaerobic, and recovery energy expenditures: 3 submaximal sets. [J]. Physiologie Appliquée Nutrition Et Métabolisme, 2012, 37(2):252. 